\title{
Tek Seviye Anterior Servikal Diskektomi ve Füzyon Sonrası Servikal Sagittal Dizilimin Değerlendirilmesi; Klinik Seri
}

\section{Evaluation of Cervical Sagittal Alignment After Single Level Anterior Cervical Discectomy and Fusion; Clinical Series}

\author{
Ülkün Ünlü Ünsal ${ }^{1 *}$ \\ ${ }^{1}$ Manisa Şehir Hastanesi, Nöroşirürji Departmanı, Manisa-Türkiye \\ e-mail: ulkununlu@ hotmail.com \\ ORCID ID: 0000-0001-5194-3138 \\ *Sorumlu Yazar / Corresponding Author: Sorumlu Yazar: Ülkün Ünlü Ünsal ${ }^{1}$ \\ Gönderim Tarihi / Received: 05.05.2020 \\ Kabul Tarihi / Accepted: 27.05.2020 \\ DOI: $10.34087 /$ cbusbed.732716 \\ $\ddot{\mathbf{O z}}$
}

Giriş ve Amaç: Servikal dizilim yaşam kalitesi ve myelopatiyle ilişkilidir. Anterior servikal diskektomi ve füzyon'un amacı nöral yapıları dekomprese etmek, servikal dizilimi korumak ve/veya restore etmektir. Bu çalışmanın amacı günümüzde yaygın olarak kullanılan anterior servikal diskektomi ve füzyon'un servikal sagittal dizilim üzerine etkisini değerlendirmektir.

Gereç ve Yöntemler: Tek seviye dejeneratif servikal disk hernisi nedeniyle anterior servikal diskektomi ve füzyon uygulanan 16 hastayı ortalama 16 ay takip edilmesinin ardından retrospektif olarak değerlendirdik. Radyolojik değerlendirme için preoperatif ve postoperatif 12. ayda lateral skolyoz grafisinde C1-C2, C2-C7 ve T1 slop açılarını analiz ettik. Klinik sonuçları değerlendirmek için vizüel analog skala (boyun ağrısı için) skorları incelendi.

Bulgular: Preoperatif ve postoperatif 12.ayda ölçülen servikal sagittal dizilim parametrelerinde istatistiksel olarak anlamlı fark bulunmazken; hastaların preoperatif ve postoperatif 12.ayda değerlendirilen Vizüel analog skala değerlerinde istatistiksel olarak anlamlı bir fark saptandı.

Sonuç: Tek seviye anterior servikal diskektomi ve füzyon sonrası radyolojik açıdan istatistiksel olarak anlamlı bir fark çıkmasa bile klinik olarak hastalarda belirgin bir iyileşme gözlenmiştir. Alt servikal bölgede tek seviye yapılan anterior servikal diskektomi ve füzyonun, servikal lordozu düzeltmeye olan etkisinin daha az olduğu saptanmıştır.

Anahtar Kelimeler: Anterior servikal diskektomi ve füzyon, servikal sagittal dizilim

\footnotetext{
Abstract

Objective: Cervical alignment is associated with life quality and myelopathy. The goals of anterior cervical discectomy and fusion are decompressing the neural structures, maintaining cervical alignment and/or restoring it. The aim of this study is to determine the effects of anterior cervical discectomy and fusion, which is recently widely performed, on cervical sagittal alignment.

Materials and Methods: 16 patients with single-level degenerated servical disc herniation who underwent the operation of anterior cervical discectomy and fusion were followed up for average of 16 months were evaluated retrospectively. C1-C2, C2-C7 and T1 slope angles were analyzed at the lateral scoliosis graphies preoperatively and postoperatively at 12 th months.

Results: Data showed no statistically significant difference between the measured cervical sagittal alignment parameters at preoperative and postoperative 12 months, whereas there was statistically significant difference between the Visual Analogue Scale values of the patients at preoperative and postoperative 12 months.

Conclusion: Although there was no statistically significant difference after single-level cervical discectomy and fusion radiologically, a significant improvement was observed in patients clinically. It was determined that singlelevel anterior cervical discectomy and fusion in lower cervical levels have less effect on correction of cervical lordosis. Keywords: Anterior cervical discectomy and fusion, cervical sagittal alignment
} 


\section{Giriş}

Servikal omurga, omurganın geri kalanına göre en geniş hareket aralığına izin verdiği ve aynı zamanda başın ağırlığını desteklediği için çok karmaşıktır. Servikal bölgenin bu karmaşık doğası, cerrahi düşünmeyi gerektirebilecek dizilim patolojisiyle başlayan ve kaçınılmaz olarak yol açan çeşitli bozukluklara ve komplikasyonlara kendini duyarlı hale getirir. Servikal omurgadaki dejeneratif değişiklikler sağlıkta yaşam kalitesini bozabilir ve fonksiyonelliği azaltabilir [1]. Bu dejeneratif değişiklikler çoğu zaman ağrı, radikülopati ve myelopati ile sonuçlanabilir ve bazen cerrahi gerektirebilir [2]. Dekompresif cerrahi anterior veya posterior yolla oluşturulabilir. Bugünlerde dejeneratif servikal diskektomi için en yaygın kullanilan cerrahi yöntem anterior servikal diskektomi ve füzyondur (ASDF) [3]. İlk olarak Smith ve Robinson tarafından tanımlanmış olan [4]; anterior servikal diskektomi ve füzyon dejenere diskin patolojik omurilik seviyesinde çıkarılmasını ve yerine otolog veya yapay kemik grefti ile paketlenmiş paralel veya açılı plastik veya titanyum kafes yerleştirilmesini içerir. Ayrıca özellikle fokal kifoz olmak üzere bazı servikal deformitelerin düzeltilmesinde de fayda sağladığı gösterilmiştir [5]. Servikal sagittal denge son dönemlerde servikal dejeneratif hastalıkların ortaya çıkmasında radyolojik ve klinik sonuçları belirlemek için önemli bir faktör olarak büyük ilgi gördü. Servikal omurganın dizilimdeki bir problem aynı zamanda servikal myelopatinin gelişiminde önemli bir rol oynar çünkü; servikal deformite spinal kord kompresyonuna ve kord tansiyonuna yol açar [6]. Buna ek olarak postoperatif dizilim bozukluğu ve kifoz komşu segment hastalığının gelişimiyle ilişkilendirilmiştir [6,7]. Geçmişte, spinal dizilimde uyumsuzluk ve sağlıkta yaşam kalitesi arasındaki ilișki üzerine yapılan araştırmalar büyük ölçüde torakolomber ve pelvik bölgeler üzerinde yoğunlaşmış ve servikal omurga çok az dikkate alınmıştır. Günümüze kadar anormal servikal dizilimi düzeltmek için cerrahi endikasyonlar iyi tanımlanmamıştır ve elde edilecek düzeltme miktarını ele almak için belirlenmiş bir standart yoktur. $\mathrm{Bu}$ çalışmanın amacı, tek seviye ASDF prosedürü uygulanan hastalarda radyolojik ve klinik sonuçları preoperatif ve postoperatif 12. ay takibinde sagittal dizilime ve boyun ağrısı için vizüel analog skala değerlerine göre karşılaştırarak dejeneratif servikal disk hastalığında sagittal dengenin restorasyonu ve sürdürülmesi açısından etkisini değerlendirmektir.

\section{Materyal ve Metot}

2.1. Çalışma dizaynı

$\mathrm{Bu}$ retrospektif çalışmaya Koç Üniversitesi Hastanesi Nöroşirürji departmanında Şubat 2017Şubat 2019 yılları arasında boyun/boyun+kol ağrısı ve/veya progresif nörolojik defisiti olan konservatif tedaviden yanıt almamış sadece C6-C7 tek seviye servikal disk hernisinden opere edilerek anterior servikal diskektomi ve füzyon yapılan 16 hasta dahil edilmiştir (Tablo 1).

Tablo 1. Hastaların özellikleri

\begin{tabular}{|c|c|c|c|c|c|}
\hline & Yaş & Cinsiyet & Şikayet & Nörolojik Defisit & Op. Seviyesi \\
\hline 1 & 70 & $\mathrm{~K}$ & Boyun ve kol ağrısı & Sağ ön kol eks. kas gücü $2 / 5$ & C6-7 \\
\hline 2 & 56 & $\mathrm{E}$ & Boyun ve kol ağrısı & Sağ ön kol fleks. kas gücü $3 / 5$ & C6-7 \\
\hline 3 & 60 & $\mathrm{E}$ & Boyun ağrıs1 & Sol ön kol eks. kas gücü $3 / 5$ & C6-7 \\
\hline 4 & 42 & $\mathrm{~K}$ & Boyun ve kol ağrısı & Sağ ön kol eks. kas gücü 4/5 & C6-7 \\
\hline 5 & 65 & $\mathrm{~K}$ & Boyun ağrısı & Sağ el bileği eks. kas gücü $3 / 5$ & C6-7 \\
\hline 6 & 45 & $\mathrm{~K}$ & Boyun ve kol ağrısı & Sol ön kol eks. kas gücü $3 / 5$ & C6-7 \\
\hline 7 & 47 & $\mathrm{~K}$ & Boyun ve kol ağrısı & Nörolojik defisit yok & C6-7 \\
\hline 8 & 53 & $\mathrm{E}$ & Boyun ağrısı & Sol ön kol eks. kas gücü 4/5 & C6-7 \\
\hline 9 & 55 & $\mathrm{~K}$ & Boyun ve kol ağrısı & Nörolojik defisit yok & C6-7 \\
\hline 10 & 49 & $\mathrm{~K}$ & Boyun ve kol ağrısı & Sol ön kol eks. kas gücü $4 / 5$ & C6-7 \\
\hline 11 & 38 & $\mathrm{~K}$ & Boyun ağrısı & Sol ön kol fleks. kas gücü $3 / 5$ & C6-7 \\
\hline 12 & 35 & $\mathrm{~K}$ & Boyun ağrısı & Nörolojik defisit yok & C6-7 \\
\hline 13 & 60 & $\mathrm{E}$ & Boyun ağrısı & Sağ ön kol fleks. kas gücü $4 / 5$ & C6-7 \\
\hline 14 & 45 & $\mathrm{E}$ & Boyun ağrısı & Sağ el bileği eks. kas gücü $4 / 5$ & C6-7 \\
\hline 15 & 50 & $\mathrm{~K}$ & Boyun ve kol ağrısı & Sol ön kol fleks.kas gücü 4/5 & C6-7 \\
\hline 16 & 50 & $\mathrm{~K}$ & Boyun ve kol ağrısı & Sol ön kol fleks. kas gücü $3 / 5$ & C6-7 \\
\hline
\end{tabular}


18 yaş altındaki hastalar ve daha önce anterior ve/veya posterior servikal cerrahi geçirmiş olan hastalar çalışmaya dahil edilmemiştir. Cerrahi işlemler tek bir akademik kurumda tek cerrah tarafından gerçekleştirildi. Hastaların bakımında yer almayan bağımsız bir cerrah verileri analiz etti. Hastaların preoperatif ve postoperatif takibinde 12.ay'da boyun ağrısı için Vizüel analog skala (VAS) değerleri ve servikal sagittal parametre verileri değerlendirildi.

\subsection{Operatif Teknik}

Hastalar genel anestezi altında standart SmithRobinson yöntemi kullanılarak mikroskop eşliğinde opere edildi. [4] Dekompresyon işlemi ardından hastanın preoperatif servikal lordoz veya kifozuna göre (preoperatif lordozu olan hastalara daha alçak kafes yerleştirilirken; preoperatif kifozu olan hastalara daha yüksek kafes yerleştirildi) kilitlipolietereterketon (PEEK) kafes yerleştirildi. Kullanılan kafes yüksekliği 5-9 mm arasındaydı.

2.3. Veri toplama ve değerlendirme kriterleri

Demografik veriler yaş, cinsiyeti, şikayet ve nörolojik durumu içerdi. On üç (13) hastanın preoperatif motor defisiti vardı. Tüm hastaların preoperatif dönemde ve postoperatif 12.ayda tüm vücudu içeren ayakta ön-arka ve lateral skolyoz grafileri çekildi. Tüm radyografik değerlendirmeler Surgimap Spine (Nemaris, Inc., New York, NY) programı kullanılarak yapıldı. Servikal sagittal parametreler lateral skolyoz grafisinde Cobb methoduyla [8] ölçüldü ve analiz edildi. C1-C2 arasındaki açı; $\mathrm{C} 1$ vertebrasının ventral ve dorsal arkının inferiorundan geçen hatla $\mathrm{C} 2$ vertebrasının korpusunun inferiorundan geçen hat arasındaki açıdır [9]. C2-C7 (CL) arası servikal lordoz açısı; C2 vertebrasının inferior uç plak'ı ile C7 vertebrasının inferior uç plak'ı arasındaki açıdır. T1 slop; T1 vertebra superior uç plak'1 ile horizontal hat arasındaki açı olarak tanımlanır (Resim A-B-C). Lordoz pozitif değer, kifoz negatif değerle ifade edildi. Klinik analiz'de preoperatif-postoperatif Vizüel analog skala (VAS)- (boyun ağrısı için) kullanıldı. Radyolojik ve klinik farklılıkları preoperatif ve postoperatif değerlendirildi (Resim D-E).
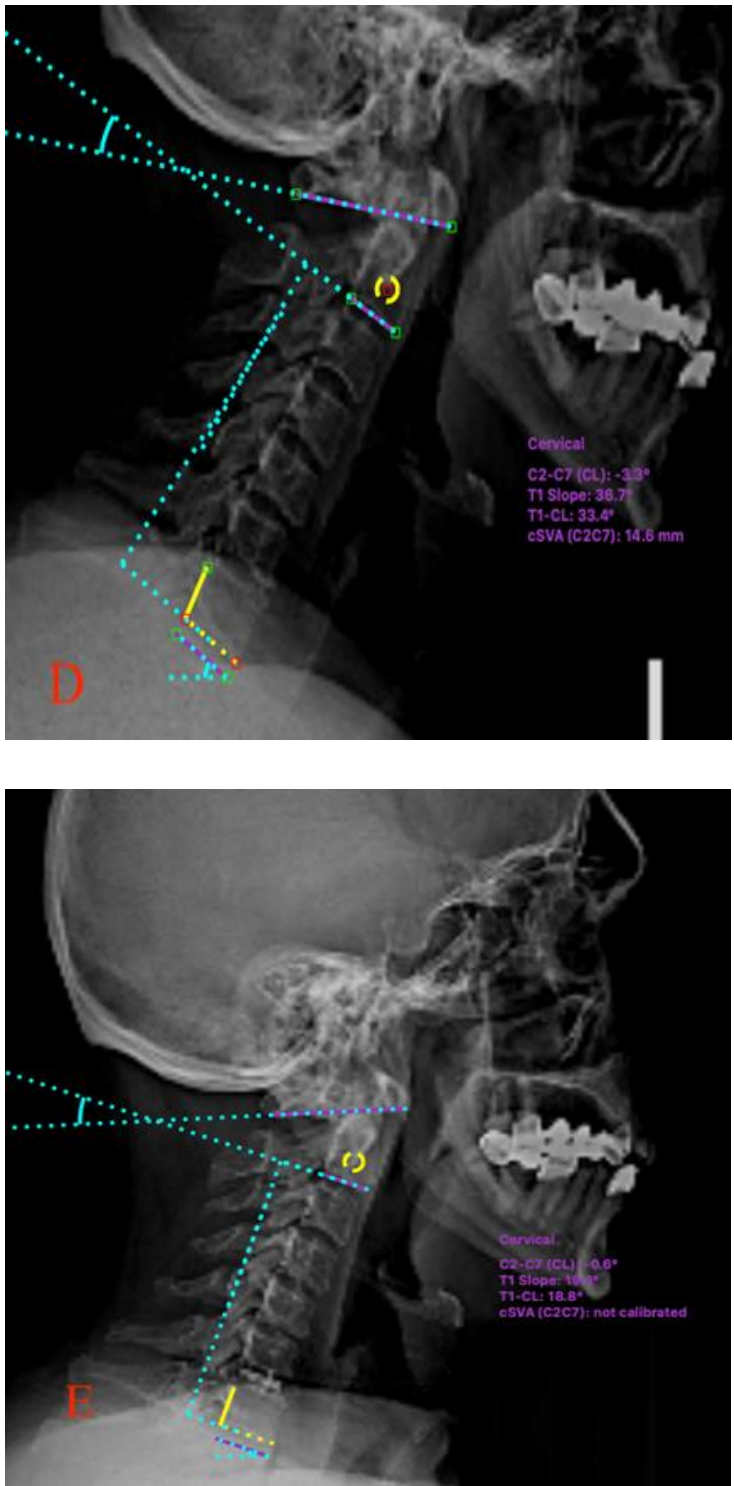

Resim-D-E: Preoperatif C2-C7 (servikal lordoz açısı) açısı -3,30 olan hastanın; Postoperatif C2-C7 açısı 0,6 $6^{\circ}$ olarak lordoz lehine değişmiştir.

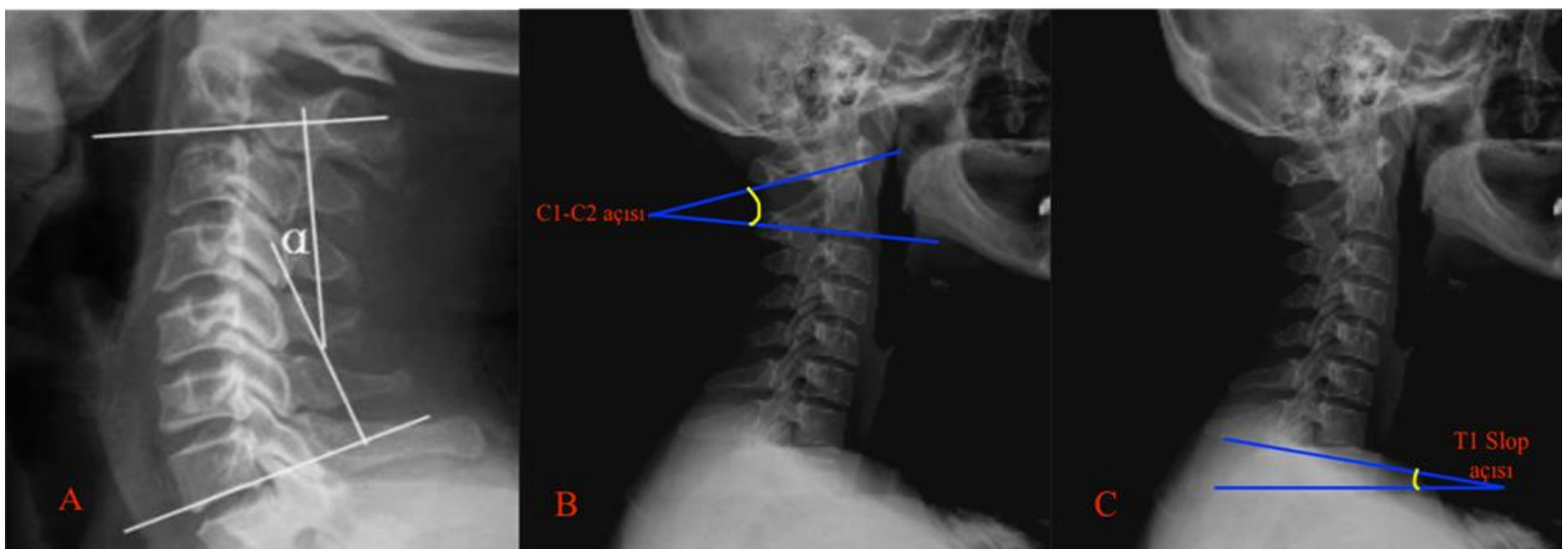

Resim-A: C2-C7 açısı; C2 ve C7 vertebra alt uç plaklarından servikal lordoz ölçümü. Resim-B: C1-C2 açıs1; C1 vertebrasının ventral ve dorsal arkının inferiorundan geçen hatla $\mathrm{C} 2$ vertebrasının korpusunun inferiorundan geçen hat arasındaki açıdır. Resim-C: T1 slop açısı; T1 vertebra superior uç plak’1 ile horizontal hat arasındaki açı olarak tanımlanır 


\section{Bulgular}

Çalışmaya dahil edilen 16 hastanın 11'i kadın, 5'I erkek idi. Yaş ortalaması 51,25 idi (aralık 35-70). Hastalar postoperatif ortalama 16 ay (aralık, $12-24$ ay) takip edildi. Preoperatif ölçülen C1-C2 açısı ortalama

$-26,8^{\circ} \pm 17,56\left(\operatorname{aral} 1 \mathrm{k},-42^{\circ}-14^{\circ}\right)$ ve postoperatif $-20,5^{\circ}$ $\pm 14,94^{\circ}$ (aralık, $-32^{\circ}-15^{\circ}$ ) ölçüldü (Mann-Whitney U testi $\mathrm{p}=0.141)$. Ortalama Cobb açısı preoperatif $-8,67^{\circ} \pm$ $9,97^{\circ}$ (aralık, $-18^{\circ}-10^{\circ}$ ), postoperatif $-8,56^{\circ} \pm 7,70^{\circ}$ (aralık, $-28^{\circ}-3^{\circ}$ ) idi (Mann-Whitney U testi, $\mathrm{p}=0.490$ ). Ortalama T1Slop preoperatif $23,9^{\circ} \pm 9,79^{\circ}\left(\operatorname{aral} 1 \mathrm{k}, 12^{\circ}\right.$ $\left.-41^{\circ}\right)$ ve postoperatif $22^{\circ} \pm 5,85^{\circ}\left(\right.$ aralik, $14^{\circ}-31^{\circ}$ ) olarak ölçüldü (Mann-Whitney U testi, p = 0.944). T1Slop ve Cobb açısı ölçümlerinde iki grup arasında istatistiksel olarak anlamlı bir fark görülmedi (Tablo-2). Preoperatif dönemde yapılan Vizüel analog skala (VAS) skoru ölçümleri ile karşılaştırıldığında, postoperatif 12.ay takibinde yapılan ölçümlerde istatistiksel olarak anlamlı bir azalma tespit edildi. Preoperatif dönemde ortalama VAS skoru 8.18 \pm 1.04 (aralık, 6-10), postoperatif dönemde 12.ayda $2.56 \pm 0.72$ (aralık, 1-4) olarak hesaplandı (sırasiyla Mann-Whitney U testi $\mathrm{p}=0.0001$ ).

3.1. Istatistiksel analiz

İstatistiksel analiz MedCalc Statistical Software ver. 12.7.7 (MedCalc Software bvba, Ostend, Belgium; http://www.medcalc.org; 2013) kullanılarak yapıldı. Tanımlayıcı istatistikler normal dağılımlı değişkenler için ortalama ve standart deviasyon değerleri ile, normal dağılımın dışında kalan değişkenler için ortalama değerler (minimum ve maksimum değerlerler) kullanılarak belirlendi. Çarpıklık katsayısı için nonparametrik istatistiksel yöntemler kullanıldı. İki normal olmayan dağılıma sahip grubun karşılaştırılması için Mann Whitney $U$ testi kullanıldı. Her iki yönlü $p$ değerinin 0.05 değerinin altında olması istatistiksel olarak anlamlı kabul edildi.

Tablo 2. Hastaların VAS değerlerinin ve servikal sagittal parametrelerinin istatistiksel analizi

\begin{tabular}{|l|l|l|l|}
\hline Değişken & Preoperatif & Postoperatif & p \\
\hline VAS & $8.18 \pm 1.04$ & $2.56 \pm 0.72$ & 0.001 \\
\hline C1-C2 açısı ( ${ }^{\circ}$ & $-26.8 \pm 17.56$ & $-20.5 \pm 14.94$ & 0.141 \\
\hline T1 slop açısı ( ${ }^{\circ}$ & $23.9 \pm 9.79$ & $22 \pm 5.85$ & 0.944 \\
\hline C2-C7 açısı (Servikal lordoz) (०) & $-8.67 \pm 9.97$ & $-8.56 \pm 7.70$ & 0.490 \\
\hline
\end{tabular}

Mann-Whitney U test

\section{Tartışma}

Servikal sagittal dizilimin sağlıkta yaşam kalitesinde önemli bir rol oynadığı konusunda artan bir farkındalık var. Klinik çalışmalar, kifozun servikal operasyondan önce ve sonra artan boyun ağrısı ile ilişkili olduğunu göstermektedir [10]. Servikal lordozun restorasyonu veya güçlendirilmesi, anterior servikal diskektomi ve füzyon (ASDF) 'deki nöral yapıların dekompresyonu kadar önemli bir cerrahi hedeftir. Naderi ve arkadaşlar'1 yaptıkları çalışmada preoperatif anormal servikal lordoz varlığı postoperatif nörolojik iyileşmenin sınırlarını tahmin etmemizi sağlayabileceğini bildirdiler [11]. Anterior servikal diskektomi ve füzyon (ASDF) şu anda servikal dejeneratif disk hastalığının cerrahi tedavisinde en yaygın cerrahi yaklaşımdır [12]. ASDF özellikle C2C7 olmak üzere sagittal dizilimde restore edilmesinde etkili bir prosedür. Literatürde sadece birkaç çalışma anterior servikal diskektomi ve füzyon'nun sagittal dizilime etkisini değerlendirdi. Jagannathan ve arkadaşlar'1 allogreft ile ASDF uygulanan 170 hastada klinik sonuçları ve sagittal dizilimi araştırdı. Preoperatif kifotik segmental açıları olan 36 hastanın hepsinde (\%21) postoperatif kifoza doğru ortalama $7,4^{\circ}$ değişiklik bildirdiler. Segmental açıdaki değișiklik ile postoperatif fonksiyonel durum arasında anlamlı bir ilişki saptanmadı. Ek olarak, ortalama C2-C7 Cobb açılarında önemli bir değişiklik saptanmadı [13]. Bizim sonuçlarımızda; hastaların preoperatif döneme göre postoperatif dönemde servikal lordozlarında düzelme saptanırken ortaya çıkan fark istatistiksel olarak anlamlı saptanmadi. Bunun nedeni olarak öne çıkan sebepler arasında ilki, bizim hastalarımızın tamamında cerrahi gerçekleştirilen seviyenin C6-7 seviyesi olması ve alt servikal bölgenin servikal lordozu sağlamada üst servikal bölgeye göre daha az etkili olması olarak değerlendirildi [14].

Ayrıca hasta sayısının az olmasına, hastaların yaşlarının yüksek olması nedeni ile dejeneratif bir omurgaya sahip olmaları ve bunun sonucunda preoperatif dönemdeki servikal sagittal dizilim parametrelerindeki anormalliklere bağlandı. Kwon ve arkadaşları anterior servikal diskektomi ve füzyon operasyonu geçirmiş 30 hastayı araştırdı; bu hastaların 4'ü plaksız kafesle opere edilmişti. Onlar artan kifozla, boyun ağrısı için artan Vizüel analog skala (VAS) değerinin korele olduğunu belirttiler [15]. Bizim serimizde de kifoz derecesi yüksek olan ve lordozdaki düzelme derecesi düşük olan hastalarda Vizüel analog skala değerlerindeki düzelme oranı daha düşük olarak saptandı. Sakai ve arkadaşları yaptıkları çalışmada; dejeneratif servikal myelopatili hastalarda anterior füzyon ve posterior servikal laminoplastiyi kıyasladılar. Onlar sonuç olarak anterior füzyondan sonra servikal sagittal dizilimin korunduğunu ancak posterior laminoplastiden sonra ise dizilimin bozulduğunu saptadılar [16]. Sonuçlarımız preoperatif ve postoperatif 12.ay'da analiz edilen servikal lordoz ve T1 slop açılarının birbirleriyle korele olduğunu göstermiş olup bu korelasyon servikal lordozun restorasyonunda da devam etmektedir. $\mathrm{Bu}$ korelasyon; Kim ve arkadaşları'nın 108 hastalık retrospektif serideki servikal 
lordoz ve T1 slop açısı arasındaki korelasyonla uyumlu bulunmuştur [17]. Gillis ve arkadaşları ayrıca fokal lordozdaki düzelmenin tüm servikal lordoz (C2-C7)'daki düzelmeyle korele olduğunu göstermiştir [18]. Bizim araştırmamızda hastaların preoperatif servikal lordoz açısı (C2-C7 arası) ile postoperatif servikal lordoz (C2C7 arası) açısı arasındaki fark istatistiksel olarak anlamlı olmasada lordoz lehine sağlanan değişimin postoperatif Vizüel analog skala skorlarında istatistiksel olarak anlamlı bir düzelme sağladığı gözlenmiştir. Bu çalışma; anormal servikal sagittal dizilime sahip olan hastalarda, alt servikal bölgede tek seviye anterior servikal diskektomi ve füzyonun, radyolojik olarak minimal düzelme sağlasa da tüm servikal lordozda düzelme sağlamadığını göstermektedir. Ayrıca hastaların klinik sonuçlarına olumlu yönde belirgin etkisi olduğu Vizüel analog skala skorlarıyla gösterilmiştir. Bunlara ek olarak bu çalışmanın sınırlı olmasının nedenleri arasında; vaka sayısının az olması, hastaların yaş ortalamasının yüksek olması nedeniyle dejeneratif omurgaya sahip olmaları ve cerrahi yapilan seviyenin alt servikal seviye (C6-C7) olması sayılabilir.

\section{Sonuç}

Anterior servikal diskektomi ve füzyon, servikal bölgede dejenerasyonu olan hastalar için servikal sagittal restorasyonu sağlamada kullanılabilen bir yöntemdir; ancak alt servikal seviyelerde yapılan anterior servikal diskektomi ve füzyonun, servikal lordozu düzeltmeye olan etkisi daha az olmaktadır. Çalışmamızda radyolojik değerlendirme sonucunda istatistiksel olarak anlamlı fark çıkmamasına rağmen klinik olarak anlamlı bir fark çıkmış ve vizüel analog skala değerlerinde belirgin düzelme gözlenmiştir. Ancak çalışmamızda az sayıda hasta sınırlaması vardır. Anterior servikal diskektomi ve füzyonun etkinliği ve servikal sagittal dizilim üzerindeki etkisi hakkında sonuç çıkarmak için daha fazla vaka sayısı gereklidir.

\section{References}

1. Ames, CP, Blondel, B, Scheer, JK, Schwab, FJ, Le Huec, JC, Massicotte, EM et al., Cervical radiographical alignment: comprehensive assessment techniques and potential importance in cervical myelopathy, Spine (Phila Pa 1976), 2013, 38, 149-160.

2. Cepoiu-Martin, M, Faris, P, Lorenzetti, D, Prefontaine, E, Noseworthy, T, Sutherland, L, Artificial cervical disc arthroplasty: a systematic review, Spine (Phila Pa 1976), 2011,36(25),1623-33.

3. Korinth, MC, Treatment of cervical degenerative disc disease: current status and trends, Zentralbl Neurochirrurgia, 2008, 69(3), 113-24.

4. Smith, GW, Robinson, RA, The treatment of certain cervical spine disorders by anterior removal of theintervertebral disc and interbody fusion, The Journal of Bone and Joint Surgery American Volume, $1958,40,607-624$

5. Shriver, MF, Lewis, DJ, Kshettry, VR, Rosenbaum, BP, Benzel, EC, Mroz, TE, Pseudoarthrosis rates in anterior cervical discec- tomy and fusion: a meta-analysis, Spine Journal, 2015, 15, 2016-2027.

6. Scheer, JK, Tang, JA, Smith, JS, Acosta, FL Jr, Protopsaltis, TS Blondel, B et al, Cervical spine alignment, sagittal deform- ity, and clinical implications: a review, Journal of Neurosurgery Spine, 2013 19, 141-159.

7. Park, MS, Kelly, MP, Lee, DH, Min, WK, Rahman, RK, Riew, KD, Sagittal alignment as a predictor of clinical adjacent segmen pathology requiring surgery after anterior cervical arthrodesis, Spine Journal, 2014, 14, 1228-1234.
8. Harrison, DE, Harrison, DD, Cailliet, R et al., Cobb method or Harrison posterior tangent method: which to choose for lateral cervical radiographic analysis, Spine (Phila Pa 1976), 2000, 25(16), 2072-2078

9. Toyama, Y, Nakazawa, H, Koyanagi, T et al, The optimum position offusion in atlanto-axial arthrodesis, Ort-hop Trans, 1994, 18, 352353.

10. Koeppen, D, Piepenbrock, C, Kroppenstedt, S et al, The influence of sagittal profile alteration and final lordosis on the clinical outcome of cervical spondylotic myelopathy, A Delta-Omega-analysis, PLoS One, 2017, 12: e0174527

11. Naderi, S, Ozgen, S, Pamir, MN, Ozek, MM, Erzen, C., Cervical spondylotic myelopathy: surgical results and factors affecting prognosis, Neurosurgery, 1998, 43, 43-49.

12. Goffin, J, Geusens, E, Vantomme, N, Quintens, E, Waerzeggers, Y, Depreitere, B et al, Long-term follow-up after interbody fusion of the cervical spine, Journal of Spinal Disorder Technology, 2004, 17, 79. $85,2004$.

13. Jagannathan, J, Shaffrey, CI, Oskouian, RJ, et al. Radiographic and clinical outcomes following single-level anterior cervical discectomy andallograft fusion without plate placement or cervical collar, Journal of Neurosurgery Spine, 2008, 8(5), 420-428.

14. Hardacker, JW, Shuford, RF, Capicotto, RN, Pryor, PW, Radiographic standing cervical segmental alignment in adult volunteers without neck symptoms, Spine, 1997, 22, 1472-1480.

15. Kwon, B, Kim, DH, Marvin, A, Jenis LG, Outcomes following anterior cervical discectomy and fusion: the role of interbody disc height, angulation, and spinous process distance, Journal of Spinal Disorder Technology, 2005,18(4), 304-308.

16. Sakai, K, Yoshii, T, Hirai, T, Arai, Y, Shinomiya, K, Okawa, A, Impact of the surgical treatment for degenerative cervical myelopathy on the preoperative cervical sagittal balance: a review of prospective comparative cohort between anterior decompression with fusion and laminoplasty, European Spine Journal, 2017, 26, 104112.

17. Kim, HJ, Choi, BW, Park, J, Pesenti, S, Lafage, V, Anterior cervical discectomy and fusion can restore cervical sagittal alignment in degenerative cervical disease, European Journal of Orthopedic Surgery and Traumatology, 2019, 29, 767-774.

18. Gillis, CC, Kaszuba, MC, Traynelis, VC, Cervical radio- graphic parameters in 1- and 2-level anterior cervical discectomy and fusion, Journal of Neurosurgery Spine, 2016, 25,421-429.

http://edergi.cbu.edu.tr/ojs/index.php/cbusbed isimli yazarın CBU-SBED başlıklı eseri bu Creative Commons Alınt1-Gayriticari4.0 Uluslararas1 Lisans1 ile lisanslanmıștır.

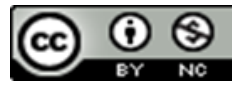

